Teknomekanik

Vol.4, No.2, Dec 2021, pp. 91 96

e-ISSN: 2621-8720 p-ISSN: 2621-9980

\title{
Development of Wireless Piezofilm Sensor for Monitoring Vehicle Suspension System
}

\author{
Muhamamad Zuhairy Zulkifli' ${ }^{1}$ Zaihasrah Masron² and Saltanat A. Omarova \\ ${ }^{1}$ Program Teknologi Pembuatan, Kolej Komuniti Segamat, Segamat 85009, Malaysia \\ ${ }^{2}$ Jabatan Kejuruteraan Petrokimia, Politeknik Tun Syed Nasir Syed Ismail, Pagoh 84600, Malaysia \\ ${ }^{3}$ Institute Metallurgy and Ore Beneficiation, Satbayev University, Almaty 050010, Republic of Kazakhstan
}

\begin{tabular}{|c|c|}
\hline Article Info & ABSTRACT \\
\hline Article history: & The use of piezoelectric sensors in the data acquisition of vibration signal for \\
\hline Received Aug 05 ${ }^{\text {th }}, 2021$ & $\begin{array}{l}\text { monitoring systems on vehicles is a practical way to determine the } \\
\text { performance of vehicle suspension systems (VSS). However, the transmission }\end{array}$ \\
\hline Revised Sep $16^{\text {th }}, 2021$ & of vibration signal data through piezoelectric sensors still relies on \\
\hline Accepted Sep 23 $3^{\text {th }}, 2021$ & $\begin{array}{l}\text { conventional techniques, such as wires, which can cause problems in areas } \\
\text { with limited space and pose a safety risk for moving vehicles. This study }\end{array}$ \\
\hline Keywords: & $\begin{array}{l}\text { developed a wireless piezofilm sensor-based data acquisition device to } \\
\text { monitor VSS using an Arduino microcontroller as a signal processor and a }\end{array}$ \\
\hline Piezofilm sensor & Bluetooth HC-05 module as a wireless communication link with a control \\
\hline Vehicle suspension system & terminal. The data acquisition process is carried out by measuring the \\
\hline Vibration & electrical signal resulting from the vibration of the piezofilm sensor caused by \\
\hline Arduino & $\begin{array}{l}\text { the dynamic motion of the VSS operation. The signal data acquired from the } \\
\text { car's body and lower arm was analyzed using the Fast Fourier Transform } \\
\text { (FFT) analytical method for comparison. The results of the analysis show that } \\
\text { the vibration increases with the increase of the car speed. It found that the } \\
\text { vibration at the lower arm of the car is higher than the body part. It can } \\
\text { conclude that the developed wireless piezofilm device is effective and capable } \\
\text { of performing VSS monitoring. }\end{array}$ \\
\hline
\end{tabular}

\section{Corresponding Author:}

Muhammad Zuhairy Zulkifli,

Program Teknologi Pembuatan, Kolej Komuniti Segamat,

No. 24-34, Jalan Putra 1/1, Bandar IOI, Segamat 85000, Johor, Malaysia.

Email: zuhairy@kkseg.edu.my

\section{INTRODUCTION}

A suspension system refers to springs, shock absorbers and mechanical linkages that connect the vehicle with its wheels. It is designed to assist the handling and stop of the car (brakes) as part of an active safety system. The absence of these components can cause discomfort in driving [1]. Vehicle monitoring systems are critical to the automotive industry to identify vehicle performance conditions to prevent component failure and damage to vehicle systems. System performance or fault detection can be made based on the information obtained, such as acoustic radiation information, vibration frequency waves, oil analysis and temperature variations [2]. Monitoring the vehicle suspension system (VSS) performance can be measured by obtaining vibration information of certain parts of the vehicle body while driving. It can measure with several vibration sensors such as accelerometers, gyroscopes, ultrasound sensors and piezoelectric sensors that can collect 3D vibration signals ( $\mathrm{x}, \mathrm{y}$ and $\mathrm{z}$ axes).

A feasible way to determine the performance of car suspension systems is to use piezoelectric sensors in vibration signal data acquisition. However, the system still uses cables to convey vibration signal data from piezoelectric sensors. The existing vibration signal data acquisition systems are costly, not user-friendly and require much equipment [13]. According to [3], current monitoring systems are expensive and need to be replaced with cost-effective wireless sensor systems. Because the conventional data acquisition process is costly, the need to adopt low-cost technology allows institutions and companies access to reduce their budgets [4].

In this study, a data acquisition device is developed by designing a wireless piezofilm sensor system based on Arduino platform embedded MATLAB environment, analyzing raw signals obtained and compare the

Journal homepage: http://teknomekanik.ppj.unp.ac.id

DOI: https://doi.org/10.24036/teknomekanik.v4i2.10572 
performance of VSS using MATLAB software [14]. The main objective of this study is to develop a more practical data acquisition device based on a wireless piezofilm sensor to determine VSS performance in terms of safety and difficulty in installation and capable of monitoring VSS response.

\section{METHODS}

The development of a device begins with the collecting of information from previous studies. Next, the selection of hardware is made by obtaining the necessary components from the market, installing those components, and creating a processing program according to the schematic being prepared. Furthermore, the Arduino processing programming is linked with MATLAB software to run the data acquisition process to obtain the electrical signal response resulting from VSS operation [15]. The last step is to analyze the raw data obtained to see the relationship between signal response and VSS performance. The design is separated into two sections, namely hardware and software [16]. The device produced are based on Arduino UNO microcontroller as the signal data processor, piezofilm sensor as a transducer, Bluetooth HC-05 module as wireless communication connection, data logger shield to store raw data and $9 \mathrm{~V}$ battery as a power source to the device.

\subsection{Hardware}

Hardware installation of the wireless piezofilm sensor device based on the wiring schematic as shown in Figure 1. Hardware required in the development of this device are:

\section{Arduino UNO Microcontroller}

The Arduino Uno is an ATmega328P-based $16 \mathrm{MHz}$ quartz crystal microcontroller board with 14 digital input/output pins ( 6 pins used for PWM output), 6 analogue inputs, USB connection, a power jack, ICSP header and reset button.

\section{Piezofilm Sensor}

The sensor used in the development of this device is a piezoelectric film type that can produce a voltage in proportion to the mechanical stresses and strains and is also a very rugged sensor in use [12]. In addition, the piezofilm had a pulse signal which was then detected by electronic equipment, namely the Arduino microcontroller for this study. Therefore, this sensor is suitable for detecting vibrations resulting from the dynamic motion of the VSS as it is susceptible to any mechanical movement. In this study, two piezofilm sensors were used in the production of a wireless data acquisition device. One piezofilm is used to detect the vibration signal on the sprung mass (the car body) and another piezofilm to detect the vibration signal on the unsprung mass (the lower arm of the car).

\section{Bluetooth HC-05 Module}

The HC-05 Bluetooth module is an easy-to-use SPP (Serial Port Protocol) Bluetooth module designed for wireless serial connection preparation. Serial communication makes it easy to interact with a controller or computer. The HC-05 Bluetooth module provides a switching mode between master/slave modes to either receive or send data.

\section{Arduino Data Logger Shield}

This Data Logger Shield allows the Arduino Uno board to record piezofilm sensor data to an SD card. It is effortless to use; put this shield on the Arduino board, and it be able to record data. It also provides some beneficial features for the development of this device: the DS1307 Real Time Clock module for recording time and the SD card reader module for recording data into the SD card in FAT16 or FAT32 format. It has a maximum capacity of up to $32 \mathrm{~GB}$.

\section{9 V Battery}

A $9 \mathrm{~V}$ battery power source is required to supply power to the Arduino microcontroller and Bluetooth module; however, piezofilm sensors does not require an external power source because the voltage is generated from the mechanical stress and strains of the sensor itself. The $9 \mathrm{~V}$ battery is chosen over other power sources because it is smaller and due to Arduino board has an external voltage input range of 7 to $12 \mathrm{~V}$. Thus, it is very suitable and safe to use. 

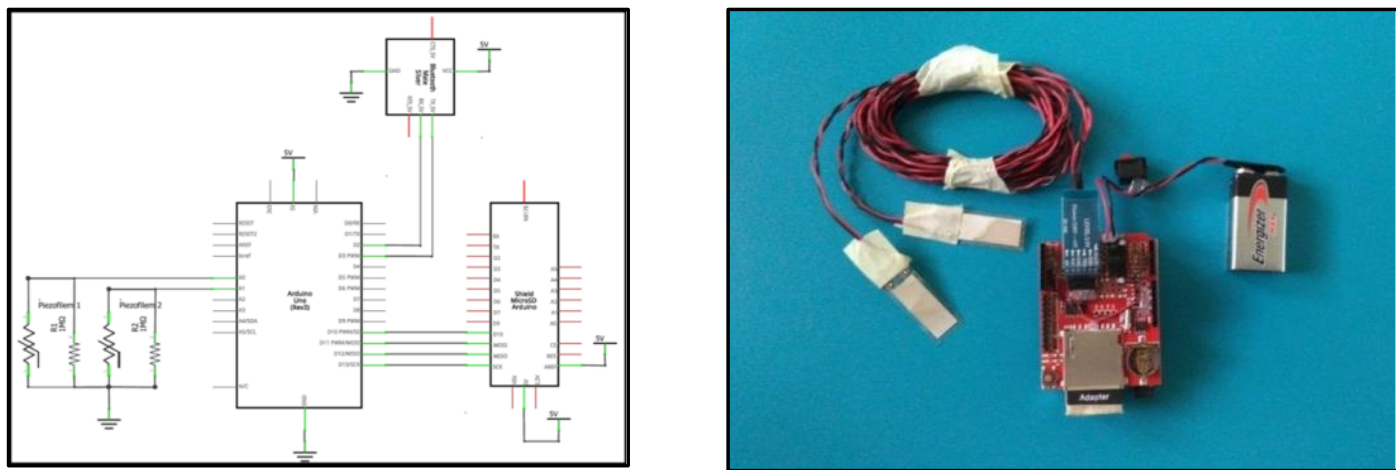

Figure 1: Hardware connection of a wireless piezofilm sensor device.

\subsection{Software}

The operating system programming for this wireless piezofilm device is divided into two sections, namely Arduino IDE and MATLAB.

1. Arduino IDE

An Arduino program code that corresponds to the work instructions for the data acquisition process using this device is designed and uploaded into this wireless piezofilm device using Arduino IDE software to instruct the Arduino microcontroller to perform the task.

2. MATLAB

MATLAB software serves as a device system controller and processes raw data for analysis to evaluate VSS performance. The Arduino platform will be embedded in the MATLAB environment to start and end the signal measurement process to perform MATLAB as a device system controller. Furthermore, MATLAB is used in conjunction with Arduino as a data analysis engine due to Arduino's weakness in complex analysis.

\subsection{Research Design}

The study was conducted on the vehicle suspension system (VSS) for Toyota's Vios model 1.5E 2010. The parameters involved in this study are the measurement time, sampling rate, vehicle speed and road surface conditions [17]. The study was carried out on a flat road in Bandar Baru Bangi, Selangor area. The measurement of the vibration signal from VSS is recorded for 5 seconds with the same sampling rate of 1000 $\mathrm{Hz}$ for each measurement. The study will be conducted at three different car speeds, that is $40 \mathrm{~km} / \mathrm{h}, 60 \mathrm{~km} / \mathrm{h}$ and $80 \mathrm{~km} / \mathrm{h}$. The speed of the car is limited to $80 \mathrm{~km} / \mathrm{h}$ in this test as a safety measure while driving.

\subsection{Data Acquisition Method}

The data acquisition process was made using a developed wireless piezofilm sensor device place in the engine compartment of the car [18]. Figure 2 and Figure 3 show the position of the sensor; piezofilm sensor (P1) is attached to the top frame of the car, namely at the top after the shock absorber (sprung mass) and piezofilm sensor (P2) is attached to the lower arm of the car, which is before connection to shock absorber (unsprung mass). The schematic of the data acquisition process is as shown in Figure 4.

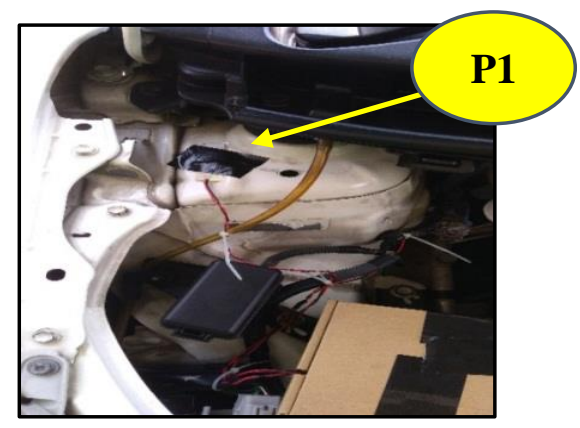

Figure 2: Position of piezofilm P1 on the upper frame of the car body

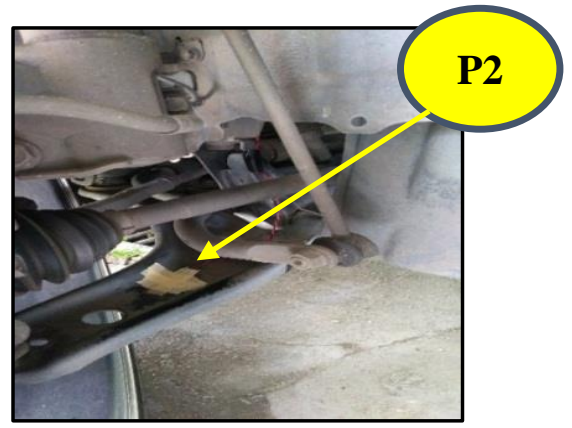

Figure 3: Position of piezofilm P2 on the lower arm of the car 
Data are recorded for 5 seconds via a designed MATLAB command. The data obtained are in the form of electrical signals (voltages) which is generated due to the vibration of two piezofilm sensors because of the reaction from the VSS operation [19]. The raw data obtained will be analyzed using MATLAB software to observe the performance of the VSS response on the tested cars.

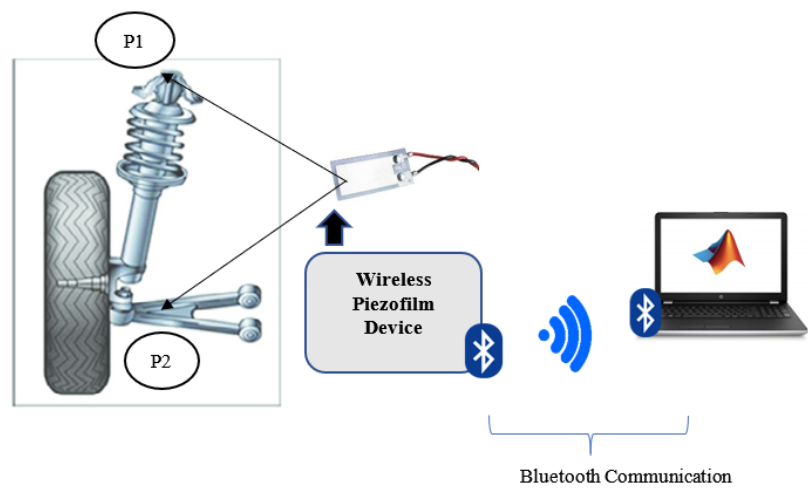

Figure 4: Schematic of the data acquisition process

\subsection{Data Analysis Methods}

Fast Fourier Transform (FFT) analysis was used to analyze the vibration signal data obtained in this study. FFT is used to convert time domain signals to frequency domains wherein the frequency domain, the same signal is composed of large sine wave components and other significant sine wave components [21]. When these components are separated, the small components will be easily visible. FFT is a powerful signal analysis tool that is widely used in various fields such as spectral analysis, digital filtration, applied mechanics, acoustics, medical imaging, capital analysis, numerical analysis, seismography, instrumentation, and communication [5]. [6] have used the FFT method to analyze the vibration signal from the car engine to observe the effectiveness of the engine support components. An evaluation of the performance of the VSS can be made by comparing the frequency domain signal spectrum for the signal response generated during the operation of the VSS in various conditions.

\section{RESULTS AND DISCUSSION}

FFT analysis aims to determine the dominant frequency found in the measured signal data to correlate the signal data obtained with the vibrations generated at two reference points, namely on the car body (P1) and lower arm (P2). Figure 5 shows a graph in the time domain and frequency domain for the $\mathrm{P} 2$ signal data for a speed of $60 \mathrm{~km} / \mathrm{h}$ obtained through FFT analysis. Meanwhile, the overall results from the FFT analysis are as shown in Table 1.

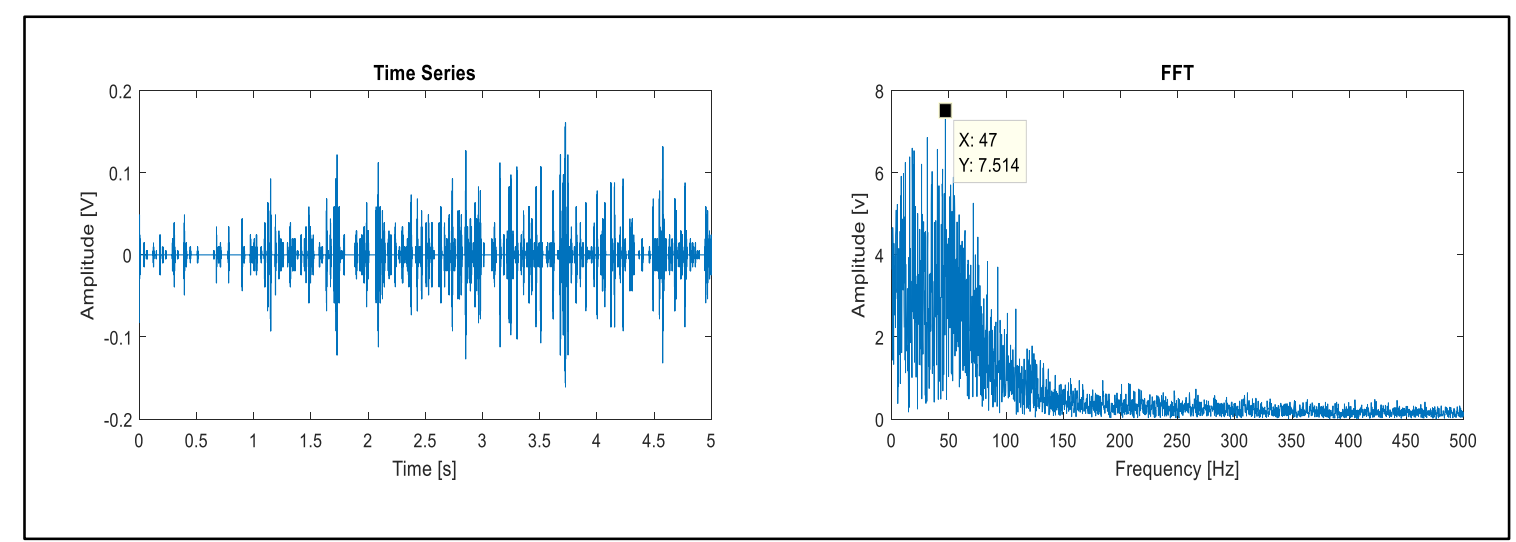

Figure 5: Graph of time domain and frequency domain for car speed $60 \mathrm{~km} / \mathrm{h}$

Journal homepage: http://teknomekanik.ppj.unp.ac.id

DOI: https://doi.org/10.24036/teknomekanik.v4i2.10572 
Table 1: Dominant frequency values for signals P1 and P2

\begin{tabular}{ccc}
\hline $\begin{array}{c}\text { Car Speed } \\
(\mathbf{k m} / \mathbf{h})\end{array}$ & $\begin{array}{c}\text { Dominant Frequency P1 } \\
(\mathbf{H z})\end{array}$ & $\begin{array}{c}\text { Dominant Frequency P2 } \\
(\mathbf{H z})\end{array}$ \\
\hline 40 & 7.4 & 40.2 \\
60 & 12 & 47 \\
80 & 12.8 & 57.2 \\
\hline
\end{tabular}

Based on the analysis data for the dominant frequency, the comparison of VSS performance can be represented in a graph such as Figure 6.

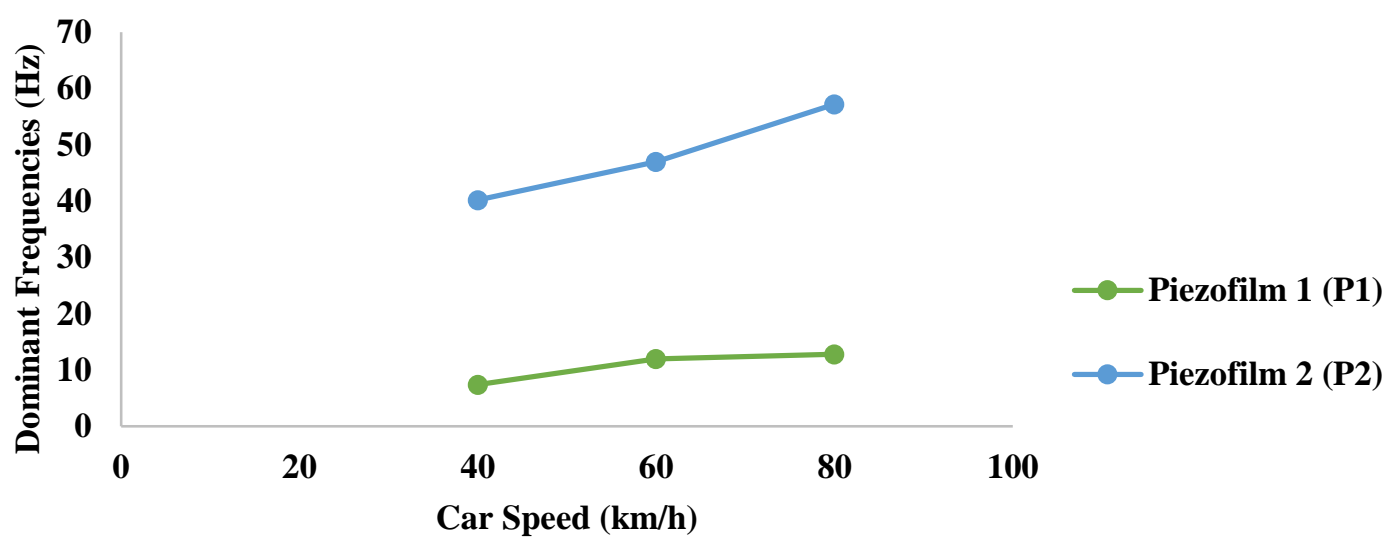

Figure 6: Comparison of dominant frequencies for P1 and P2

Referring to the graph in Figure 6, the dominant frequencies for P1 and P2 signal data are directly proportional to car speed. It can conclude that the vibration in the car has a significant relationship with the speed of the car, where the vibration increases with the increasing speed of the car. These results are in line with a study by [7], who reported that vehicle speed affects travel comfort. Increasing vehicle speed consistently increases the vertical acceleration and amplitude of the power spectrum density. A study from [8] also states that the frequency ratio increases with increasing vehicle speed.

For comparison between the vibration on the car body with the lower arm of the car, it is discovered that the dominant frequency value for P2 signal data is higher than P1. This indicates that the body of the vehicle which is in the sprung mass vibrates at a low rate because it is supported by VSS, while the lower arm which is in the unsprung mass gives high vibration because it is not supported by VSS. That is supported by [9], who found that the lower arm is a significant vibration source. Vibration from the road surface will pass through the lower arm of the car to the suspension system and subsequently the vehicle body frame. [10] stated that the vibration behaviour of components in the VSS such as axles, lower arms, torsion bars and others are in the range of 50-200 Hz. In comparison, the vibration of the vehicle body is in the frequency range of $0-30 \mathrm{~Hz}$ [11].

The study also showed that vibrations on the vehicle body were absorbed during the operation of the VSS compared to the lower arm that did not rely on the VSS, which gave a high-frequency value. The main factor affecting the driving comfort of a vehicle is the vibration caused by the unevenness of the road acting on the wheels and through the VSS transmitted to the vehicle's body [20]. The stiffness and damping of the VSS affect the vibration strength and comfort of the car. Increased VSS damping causes the vertical acceleration amplitude of the power spectrum density to decrease because vibrations have been absorbed during VSS damping [7].

\section{CONCLUSION}

Based on the FFT analysis results, it can conclude that this developed wireless data acquisition device is suitable for replacing the conventional methods. With the development of this device, it can be a valid system for data acquisition for dynamic applications that allows frequency rates up to $1000 \mathrm{~Hz}$, with a resolution of 10 bits and an input voltage between 0 to $5 \mathrm{~V}$, via Bluetooth communication. This device can also provide convenience in monitoring VSS performance, especially to vehicle owners or vehicle workshop operators,

Journal homepage: http://teknomekanik.ppj.unp.ac.id

DOI: $\underline{\text { https://doi.org/10.24036/teknomekanik.v4i2.10572 }}$ 
because it is more practical than the existing system regarding cost, difficulty level and safety during VSS monitoring. Its simple design and small size make this device easy to move and store. The device also provides an intelligent monitoring system since it is developed using microelectronic technology that can process data digitally and at high speed. The capability of this device in the acquisition of VSS data can apply for monitoring other systems such as monitoring machine operation, vibration on structures and so on.

\section{REFERENCES}

[1] Dixon, J. C. The Shock Absorber Handbook. Second Edition. West Sussex: John Wiley \& Sons Ltd. 2007

[2] Samhouri, M, S., Mota, T., Martins, P., Cotta, C., \& Correia, M. An Intelligent Opportunistic Maintenance (OM) System: A Genetic Algorithm Approach. Jordan Journal of Mechanical and Industrial Engineering. 2009; 9(10): 246-251.

[3] Abraham, S., \& Li, X. A cost-effective Wireless Sensor Network System for Indoor Air Quality Monitoring Applications. Procedia Computer Science, 2014; 34: 165-171.

[4] González, A., Olazagoitia, J. L., \& Vinolas, J. A Low-cost Data Acquisition System for Automobile Dynamics Applications. In Sensors (Switzerland). 2018; 18(2).

[5] Patel, V. K., \& Patel, M. N. Development of Smart Sensing Unit for Vibration Measurement by Embedding Accelerometer with the Arduino Microcontroller. International Journal of Instrumentation Science. 2017; 6(1): 1-7.

[6] Ahirrao, N. S., Bhosle, S. P., \& Nehete, D. V. Dynamics and Vibration Measurements in Engines. Procedia Manufacturing. 2018; 20: 434-439.

[7] Gao, J., \& Chen, K. Frequency-Domain Simulation and Analysis of Vehicle Ride Comfort Based on Virtual Proving Ground. International Journal of Intelligent Engineering and Systems. 2011; 4(3): 1-8.

[8] Dahil, L. Effect on the Vibration of the Suspension System. Metalurgija. 2017; 56(3-4): 375-378.

[9] Kim, Y. D., Jeong, J. E., Park, J. S., Yang, I. H., Park, T. S., Muhamad, P. B., Choi, D. H., \& Oh, J. E. Optimization of the Lower Arm of A Vehicle Suspension System for Road Noise Reduction by Sensitivity Analysis. Mechanism and Machine Theory. 2013; 69: 278-302.

[10] Georgiev, Z., \& Kunchev, L. Study of the Vibrational Behaviour of the Components of a Car Suspension. MATEC Web of Conferences. 2018; 234.

[11] Taghizadeh-Alisaraei, A. Analysis of Annoying Shocks Transferred from Tractor Seat Using Vibration Signals and Statistical Methods. Computers and Electronics in Agriculture. 2017; 141: 160-170.

[12] Mat Isa, C. M., Mustaffa, N. K., Joseph, E. O., \& Preece, C. N. Development of Psychomotor Skill and Programme Outcome Attainment of Civil Engineering Students in Malaysia. Asian Journal of Vocational Education And Humanities, 2020, 1(2), 9-24. https://doi.org/10.53797/ajvah.v1i2.2.2020

[13] Abu Bakar, R., Rahmatullah, B., Munastiwi, E., \& Dheyab, O. A confirmatory analysis of the prevention insider threat in organization information system. Journal of Technology and Humanities, 2021, 2(1), 2030.

[14] Elhorst, J. P. Matlab software for spatial panels. International Regional Science Review, 2014, 37(3), 389405.

[15] Herrera, A. M., Suhandri, H. F., Realini, E., Reguzzoni, M., \& de Lacy, M. C. goGPS: open-source MATLAB software. GPS solutions, 2016, 20(3), 595-603.

[16] Gupta, R. K. Co-synthesis of hardware and software for digital embedded systems 2012, (Vol. 329). Springer Science \& Business Media.

[17] Ngatiman, N. A., Nuawi, M. Z., \& Abdullah, S. Z-Freq: Signal Analysis-Based Gasoline Engine Monitoring Technique Using Piezo-Film Sensor. International Journal of Mechanical Engineering and Technology, 2018, 9(5), 897-910.

[18] Atalay, A., Atalay, O., Husain, M. D., Fernando, A., \& Potluri, P. Piezofilm yarn sensor-integrated knitted fabric for healthcare applications. Journal of Industrial Textiles, 2017, 47(4), 505-521.

[19] Mirow, P. High Resolution Piezo Film Sensor Systems for Automotive Applications. In Advanced Microsystems for Automotive Applications 2003, 249-259). Springer, Berlin, Heidelberg.

[20] Mironov, A., Priklonskiy, A., Mironovs, D., \& Doronkin, P. Application of deformation sensors for structural health monitoring of transport vehicles. In International Conference on Reliability and Statistics in Transportation and Communication, 2019 October, 162-175). Springer, Cham.

[21] Dung, C. V., \& Sasaki, E. Fundamental investigation on applicability of Piezofilm Sensor in sensing lowfrequency structural response of bridges. In Transforming the Future of Infrastructure through Smarter Information: Proceedings of the International Conference on Smart Infrastructure and ConstructionConstruction, 27-29 June 2016 (pp. 265-270). ICE Publishing. 